\title{
Effect of different cleansers on the weight and ion release of removable partial denture: an in vitro study
}

\author{
Daniela N.B. FELIPUCCI ${ }^{1}$, Letícia R. DAVI ${ }^{2}$, Helena F.O. PARANHOS ${ }^{2}$, Osvaldo L. BEZZON ${ }^{2}$, Rodrigo F. SILVA ${ }^{3}$, \\ Fernando BARBOSA JUNIOR ${ }^{4}$, Valéria O. PAGNANO ${ }^{2}$
}

\begin{abstract}
1- Graduate student, Department of Dental Materials and Prosthodontics, Ribeirão Preto Dental School, University of São Paulo, Ribeirão Preto, SP, Brazil. 2- MSc, PhD, Department of Dental Materials and Prosthodontics, Ribeirão Preto Dental School, University of São Paulo, Ribeirão Preto, SP, Brazil.

3- MSc, PhD, Department of Chemistry, School of Philosophy, Sciences and Languages, University of São Paulo, Ribeirão Preto, SP, Brazil.

4- MSc, PhD, Department of Clinical, Toxicological and Bromatological Analysis, School of Pharmaceutical Sciences of Ribeirão Preto, University of São Paulo, Ribeirão Preto, SP, Brazil
\end{abstract}

Corresponding address: Profa. Dra. Valéria Oliveira Pagnano - Faculdade de Odontologia de Ribeirão Preto - USP - Departamento de Materiais Dentários e Prótese - Av. do Café, s/n, Monte Alegre - 14090-110 - Ribeirão Preto - São Paulo - Brazil - Phone: +55-16-3602-4795 - e-mail: valpag@forp.usp.br

Received: August 14, 2009 - Modification: April 30, 2010 - Accepted: October 26, 2010

\section{ABSTRACT}

\begin{abstract}
O bjective: Removable partial dentures (RPD) require different hygiene care, and association of brushing and chemical cleansing is the most recommended to control biofilm formation. However, the effect of cleansers has not been evaluated in RPD metallic components. The aim of this study was to evaluate in vitro the effect of different denture cleansers on the weight and ion release of RPD. Material and Methods: Five specimens

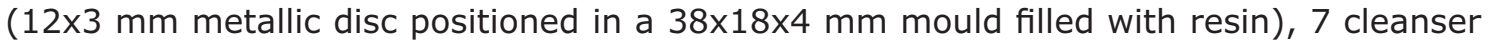
agents [Periogard (PE), Cepacol (CE), Corega Tabs (CT), Medical Interporous (MI), Polident (PO), $0.05 \%$ sodium hypochlorite $(\mathrm{NaOCl})$, and distilled water (DW) (control)] and 2 cobaltchromium alloys [DeguDent (DD), and VeraPDI (VPDI)] were used for each experimental situation. One hundred and eighty immersions were performed and the weight was analyzed with a high precision analytic balance. Data were recorded before and after the immersions. The ion release was analyzed using mass spectrometry with inductively coupled plasma. Data were analyzed by two-way ANOVA and Tukey HSD post hoc test at $5 \%$ significance level. Results: Statistical analysis showed that CT and MI had higher values of weight loss with higher change in VPDI alloy compared to DD. The solutions that caused more ion release were $\mathrm{NaOCl}$ and MI. Conclusions: It may be concluded that $0.05 \% \mathrm{NaOCl}$ and Medical Interporous tablets are not suitable as auxiliary chemical solutions for RPD care.
\end{abstract}

Key words: Removable partial denture. Denture cleansers. Chromium alloys.

\section{INTRODUCTION}

Proper cleaning of removable partial dentures (RPD) is important to maintain healthy oral mucosa. Microbial biofilm on the tissues and denture surface is a significant adjuvant in the pathogenesis of denture stomatitis $^{5,6}$. Surface roughness may contribute to the positively correlated rate of microbial colonization, adhesion of microorganisms and biofilm maturation on surfaces ${ }^{4,8,11,14,16,20}$.

Webb, et al. ${ }^{22}$ (2005) showed that denture biofilm control techniques that use only brushing are not as effective as chemical cleansing in reducing denture biofilm and preventing denture stomatitis associated with Candida. Immersion denture cleansers can be divided into 5 classes: alkaline peroxides, alkaline hypochlorite, diluted acids, disinfecting agents, and enzymes ${ }^{5,15}$. The association of mechanical and chemical methods seems to be the ideal protocol ${ }^{3,15,17}$.

RPD frameworks are usually fabricated with cobalt-chromium (Co-Cr) alloys. Because these alloys can corrode or stain as a result of surface contact with the chlorine or oxygen presents in some commercial cleansers, RPD wearers must be instructed about the correct selection of cleansing agents ${ }^{18,19}$.

Jagger and Harrison ${ }^{9}$ (1995) observed that the patients do not receive correct professional instructions about how to clean their dentures. They 
overclean the dentures, using homecare products, which could cause harmful effects. One of the required properties for an ideal denture cleanser is not to cause deleterious effects to the material. It is a critical point when considering the use of the products routinely indicated for complete dentures to clean RPD. The alkaline hypochlorite use in resin bases can be harmful to the $\mathrm{Co}-\mathrm{Cr}$ frameworks. These undesirable effects can be either tarnish (surface discoloration) or corrosion (surface pitting) ${ }^{2}$.

In view of the importance of a correct orientation to the patients concerning the more suitable auxiliary methods of cleansing, the aim of this study was to evaluate in vitro the effect of different denture cleansers on the integrity of the Co-Cr alloy used for fabricating RPD. The null hypothesis of this study is that the solutions will have no deleterious effect on the two Co-Cr alloys studied. It is the first time that a low hypochlorite concentration with proven antimicrobial effect in a short period of time ${ }^{3}$ is tested for cleaning of RPD metallic components. Webb, et. al. ${ }^{22}$ (2002) suggested the use of a smaller concentration $(0.02 \%)$ with longer immersion time (10 h) for sterilization, but it was not the focus of this study. In spite of this, hypochlorite has some advantages that must be considered such as the low cost, accessibility and effective biofilm removal.

\section{MATERIAL AND METHODS}

Two trademarks of alternative Co-Cr alloys were used for this study (Figure 1). Seventy disk-shaped wax patterns (12 $\mathrm{mm}$ in diameter x $3 \mathrm{~mm}$ thick) were obtained using a Teflon matrix. Thirty-five wax patterns were sprued, invested and cast in each alloy according to manufacturer's instructions. After casting, the specimens were finished with 220-, 400- and 600-grit sandpaper (Norton Abrasives, Saint-Gobain Abrasivos Ltda., Vinhedo, SP, Brazil) in a polishing machine (Model DPU-10, Struers, Ballerup, CO, Denmark) under refrigeration. The cast specimens were then inserted in rectangular places previously prepared with a Teflon rectangular matrix (38 $\mathrm{mm} \times 18 \mathrm{~mm} \times 4 \mathrm{~mm}$ ) using the conventional dental stone molding technique (Densite, Dentsply Ind. Com. Ltda., Petrópolis, RJ, Brazil). Before packing the heat-cured acrylic resin (Lucitone 550, Dentsply Ind. Com. Ltda), the casting disc was centered in the left side of each rectangular mold and the mold was isolated with a thin layer of separating medium (Cel-Lac, S.S. White Artigos Odontológicos
Ltda., Rio de Janeiro, RJ, Brazil). The cure cycle was in water at $73^{\circ} \mathrm{C}$ for $90 \mathrm{~min}$ and at $94^{\circ} \mathrm{C}$ for 30 min. After processing, all specimens were polished in the same machine under refrigeration, followed by polishing cloths and $1-\mu \mathrm{m}$ diamond suspension (Pasta de Diamante Natural, Fortel Ind. Com, São Paulo, SP, Brazil). All specimens were stored in distilled water at $37 \pm 1^{\circ} \mathrm{C}$ for $50 \pm 2 \mathrm{~h}$, to eliminate the residual monomer.

The specimens were dried with absorbent paper and stored in containers away from moisture and heat and were randomly distributed into the 7 groups for each alloy; each group was composed of 5 samples, according to the alloy and cleansing treatment. The specimens were preweighted in an analytical balance accurate to a tenth of a milligram (Model A200DS, Denver Instr. Company, Denver, CO, USA), which was calibrated before each measurement.

Subsequently to the initial measurements (TO), the effervescent cleanser solutions were prepared by adding one tablet of each cleanser, Corega Tabs (Corega Tabs, Stafford-Miller Ind., Rio de Janeiro, RJ, Brazil), Medical Interporous (Medical Interporous, MST Laboratories AG, Vaduz, Liechtenstein) or Polident (Polident, GlaxoSmithKline, Philadelphia, $\mathrm{PA}$, USA) to $200 \mathrm{~mL}$ of distilled water at $45^{\circ} \mathrm{C}$ as recommended by the manufacturer. The groups were stored in an oven (Model DL-AF, DeLeo Equipamentos Laboratoriais, Porto Alegre, RS, Brazil) to keep the temperature. For the storage in the solution, the specimens were positioned in a device developed to this study. The time recommended by the manufacturer was simulated 180 times. For the mouth rinses, Periogard (Colgate-Palmolive Ind. Bras., Osasco, SP, Brazil) or Cepacol (Sanofi-Aventis Farmacêutica Ltda, Suzano, SP, Brazil), sodium hypochlorite ( $\mathrm{NaOCl}$ ) (Q-Boa, Anhembi S/A, Osasco, $\mathrm{SP}$, Brazil) and distilled water group, the immersion time was fixed in $10 \mathrm{~min}$, also performing 180 immersions. All solutions were renewed every $8 \mathrm{~h}$, as suggested by Ünlü, Altay and Sahmali21 (1996). The containers with the solutions were air-tight and no changes with the environment were done. Furthermore, the manufacturers were consulted and confirmed that the solutions had activity stability in this period of time without changing. After immersion in the respective solutions, each specimen was washed with distilled water for $10 \mathrm{~s}$. After all the immersions, the second weight measurements (T1) were done in the same way as described for the initial analysis. The difference was calculated.

\begin{tabular}{|c|c|c|}
\hline Trademark & Manufacturer & Composition \\
\hline DeguDent $^{\mathrm{TM}}$ & Dentsply Ind. e Com. Ltda, São Paulo, SP, Brazil & $\begin{array}{c}\text { Co }(64.8 \%), \operatorname{Cr}(28.5 \%) \\
\text { Mo }(5.3 \%), \operatorname{Si~}(0.5 \%), \operatorname{Mn}(0.5 \%), C(0.4 \%)\end{array}$ \\
\hline Vera PDI® & Aalba Dent. Inc., Cordelia, CA, USA & Co $(63.5 \%), \operatorname{Cr}(27 \%)$, Mo (5.5\%) \\
\hline
\end{tabular}

Figure 1- Alloys 
Ion release was analyzed using an inductively coupled plasma mass spectrometry - ICP-MS (Model Elan DRC II, Perkin Elmer Sciex, City of Waltham, MA, USA). The containers were disinfected using a hydrochloric acid solution and washed with distilled water. One sample of each solution was collected before the immersion and another sample at the end of the immersions. The solutions were analyzed, and the spectrometer was calibrated to recognize the cobalt and chromium ions.

The results of weight loss were subjected to twoway ANOVA and Tukey's post hoc test. All tests were performed with the confidence at an alpha level of 0.05 .

\section{RESULTS}

The weight changes $(\mathrm{g})$ were recorded as the difference between the weight values in each period of time (T0 and T1). Since the data had a nonnormal distribution, ANOVA was performed after logarithmic transformation (normal distributions) of the original data and Tukey post hoc test. There was significant difference among the solutions $(p=0.015)$ and between the alloys $(p=0.00)$. Medical Interporous and Corega Tabs caused the highest values of weight loss (Table 1 ). The mean values and standard deviations for weight changes of the alloys are presented in Table 2. The Vera PDI showed more weight change than the DeguDent alloy. There was no statistically significant difference when the interactions were evaluated.

The values of ion release were obtained using the ICP-MS method. It was recorded the quantity of cobalt and chromium ions in each empty solution. After the immersions, the solutions were collected and submitted to analysis. The results are presented in Table 3.

It was observed increased release of ions in the solutions after the immersions. Comparing the results, it is possible to note that Vera PDI had a greater quantity of released ions. Among the solutions, $\mathrm{NaOCl}$ and Medical Interporous presented the highest values of ion release.

Table 1- Means and standard deviation (SD) of weight loss $(\mathrm{g})$ of the alloys after immersion in the solutions

\begin{tabular}{lc}
\hline Solution & Mean (SD) \\
\hline Distilled Water & $0.004(0.002)^{\mathrm{a}}$ \\
\hline Sodium Hypochlorite & $0.005(0.003)^{\mathrm{a}}$ \\
\hline Periogard & $0.005(0.004)^{\mathrm{a}}$ \\
Cepacol & $0.006(0.004)^{\mathrm{a}}$ \\
Corega Tabs & $0.009(0.006)^{\mathrm{b}}$ \\
Medical Interporous & $0.011(0.003)^{\mathrm{b}}$ \\
\hline Polident & $0.005(0.005)^{\mathrm{a}}$ \\
\hline
\end{tabular}

Mean values followed by distinct letters are statistically different $(p<0.05)$. The Tukey value is 0.34581

Table 2- Means and standard deviation (SD) of weight loss $(\mathrm{g})$ of the alloys

\begin{tabular}{cc}
\hline Alloy & Mean (SD) \\
\hline DeguDent & $0.003(0.002)^{\mathrm{a}}$ \\
VeraPDI & $0.010(0.006)^{\mathrm{b}}$ \\
\hline
\end{tabular}

Mean values followed by distinct letters are statistically different $(p<0.05)$

Table 3- Absolute values of ion release $(\mu \mathrm{g} / \mathrm{L})$

\begin{tabular}{lcccc}
\hline Solutions & Ions & Initial & DeguDent & Vera PDI \\
\hline Distilled Water & Co & 0.412 & 3,788 & 5,538 \\
\hline Sodium Hypochlorite & Cr & 14,686 & 22,208 & 28,109 \\
\hline Periogard & Co & 0.013 & 5112,351 & 2484,714 \\
\hline Cepacol & Cr & 4,976 & 5159,736 & 5747,293 \\
\hline Corega Tabs & Co & 0.264 & 4,234 & 3,102 \\
\hline Medical Interporous & Cr & 1444,133 & 1481,706 & 1478,518 \\
\hline Co & 0.425 & 4,156 & 4,272 \\
\hline Polident & Cr & 1378,756 & 1442,802 & 1437,308 \\
\hline & Co & 0.168 & 97,024 & 169,355 \\
\hline & Cr & 251,697 & 303,798 & 454,318 \\
\hline
\end{tabular}




\section{DISCUSSION}

The aim of this study was to evaluate the effects of 6 experimental solutions on the cleaning RPD. It was used the dilution of $0.05 \% \mathrm{NaOCl}$, which was the lowest concentration found in the literature as adjuvant to hygiene care of complete dentures, with antimicrobial effect ${ }^{3}$. No effect in metallic frameworks has been reported in the literature using this concentration. The literature has shown that $0.5 \%, 1 \%$ or more concentrate solutions can cause harmful effects in metallic components. Sodium perborate-based effervescent tablets (Corega Tabs and Polident) were included in the study in order to compare the methods usually indicated for complete dentures from manufacturers that also indicate the use of these tablets for metallic components without deleterious effects. In the acid category, a citric acid-based tab recently introduced in the market (Medical Interporous) was used, with the manufacturer's indication of use in metallic components with no deleterious effects. Cepacol $(0.005 \%$ cetylpyridinium chloride) and Periogard $(0.12 \%$ chlorhexidine gluconate) rinsing solutions were also evaluated for their antimicrobial effects ${ }^{7,12,13}$. Distilled water was used as control. Two Co-Cr alloys with similar compositions were evaluated with the aim of comparing the ion release resistance of the alloys.

Weight change of the alloys was evaluated in this study. Keyf and Güngör ${ }^{10}$ (2003) found no significant weight change of $\mathrm{Co}-\mathrm{Cr}$ alloy after immersion in Corega Tabs, Axion and tap water. In the present study, there was significant difference among the solutions. The commercial cleansing tablet affects the reflectance of the surface, but the corrosive effect in $\mathrm{Co}-\mathrm{Cr}$ alloy was less accentuated than the bleaching effect. In the present study, commercial bleach was not used in the comparison, only different trademarks of cleansing tablets. The Medical Interporous and Corega Tabs caused the highest values of weight loss. Comparing the alloys, it was possible to note that the Vera PDI alloy had lower resistance. These results are in accordance with those of ionic releasing, with a greater release from the Vera PDI alloy. Comparing the solutions, $\mathrm{NaOCl}$ and Medical Interporous caused the highest ion release, suggesting corrosion. A total of 180 immersions were simulated, but it is important to consider that the longevity of RPD is at least 5 years. If this ion release continues, undesirable effects might appear, such as brightness loss, porosity, and then biofilm accumulation $4,8,14,16,20$.

Although had presented high values of weight loss, the evaluated mouth rinses did not cause any significant deleterious effect to the components in comparison to Medical Interporous and Corega Tabs. It is important to note that the present evaluation did not consider the artificial teeth and some studies have suggested that chlorhexidine may cause tarnishes in these components ${ }^{1,2}$.

The objective of this study was to evaluate commercial products to be adjuvant in dentures cleaning and not substitutes to the mechanical method. These solutions must be used combined with brushing and the sum of antimicrobial effect must be considered. It was not the scope of this study to evaluate the antimicrobial effect of any solution, but further studies should evaluate the possibilities of using diluted mouthrinses, if their effectiveness is proven. It will reflect directly in the patients' daily financial investment to denture care.

\section{CONCLUSIONS}

It was observed that $0.05 \% \mathrm{NaOCl}$ is not suitable to be an auxiliary solution in the RPD care because of its corrosion potential. Medical Interporous and $0.05 \% \mathrm{NaOCl}$ caused a high ion release. Corega Tabs and Medical Interporous caused the highest weight loss after the simulation of 180 immersions.

\section{REFERENCES}

1- Abelson DC. Denture plaque and denture cleansers: review of the literature. Gerodontics. 1985;1:202-6.

2- Backenstose WM, Wells JG. Side effects of immersion-type cleansers on the metal components of dentures. J Prosthet Dent. 1977;37:615-21.

3- Barnabé W, Mendonça Neto T, Pimenta FC, Pegoraro LF, Scolaro JM. Efficacy of sodium hypochlorite and coconut soap used as disinfecting agents in the reduction of denture stomatitis, Streptococcus mutans and Candida albicans. J Oral Rehabil. 2004;31:453-9.

4- Berger JC, Driscoll CF, Romberg E, Luo Q, Thompson G. Surface roughness of denture base acrylic resins after processing and after polishing. J Prosthodont. 2006;15:180-6.

5- Budtz-Jørgensen E. Materials and methods for cleaning dentures. J Prosthet Dent. 1979;42:619-23.

6- Budtz-Jørgensen E, Stenderup A, Grabowski M. An epidemiologic study of yeasts in elderly denture wearers. Community Dent Oral Epidemiol. 1975;3:115-9.

7- Franco-Neto CA, Parolo CC, Rösing CK, Maltz M. Comparative analysis of the effect of two chlorhexidine mouthrinses on plaque accumulation and gingival bleeding. Braz Oral Res. 2008;22:13944.

8- Glass RT, Bullard JW, Conrad RS, Blewett EL. Evaluation of the sanitization effectiveness of a denture-cleaning product on dentures contaminated with known microbial flora. An in vitro study. Quintessence Int. 2004;35:194-9.

9- Jagger DC, Harrison A. Denture cleansing - the best approach. Br Dent J. 1995;178:413-7.

10- Keyf F, Güngör T. Comparison of effects of bleach and cleansing tablet on reflectance and surface changes of a dental alloy used for removable partial dentures. J Biomater Appl. 2003;18:5-14. 11- Kuhar M, Funduk N. Effects of polishing techniques on the surface roughness of acrylic denture base resins. J Prosthet Dent. 2005; $93: 76-85$.

12- Lessa FC, Enoki C, Ito IY, Faria G, Matsumoto MA, Nelson-Filho P. In-vivo evaluation of the bacterial contamination and disinfection of acrylic baseplates of removable orthodontic appliances. Am J Orthod Dentofacial Orthop. 2007;131:e11-7. 
13- Menendez A, Li F, Michalek SM, Kirk K, Makhija SK, Childers NK. Comparative analysis of the antibacterial effects of combined mouthrinses on Streptococcus mutans. Oral Microbiol Immunol. 2005;20:31-4.

14- Morgan TD, Wilson M. The effects of surface roughness and type of denture acrylic on biofilm formation by Streptococcus oralis in a constant depth film fermentor. J Appl Microbiol. 2001;91:47-53.

15- Nikawa H, Hamada T, Yamashiro H, Kumagai H. A review of in vitro and in vivo methods to evaluate the efficacy of denture cleansers. Int J Prosthodont. 1999;12:153-9.

16- Nikawa $\mathrm{H}$, Jin $\mathrm{C}$, Makihira S, Egusa $\mathrm{H}$, Hamada T, Kumagai $\mathrm{H}$. Biofilm formation of Candida albicans on the surfaces of deteriored soft denture lining materials caused by denture cleansers in vitro. J Oral Reahabil. 2003;30:243-50.

17- Paranhos HFO, Silva-Lovato $\mathrm{CH}$, Souza RF, Cruz PC, Freitas KM, Peracini A. Effects of mechanical and chemical methods on denture biofilm accumulation. J Oral Rehabil. 2007;34:606-12.
18- Ribeiro DG, Pavarina AC, Giampaolo ET, Machado AL, Jorge JH, Garcia PP. Effect of oral hygiene education and motivation on removable partial denture wearers: longitudinal study. Gerodontology. 2009;26:150-6.

19- Rodrigues Garcia RC, Souza Júnior JA, Rached RN, Del Bel Cury AA. Effect of denture cleansers on the surface roughness and hardness of a microwave-cured acrylic resin and dental alloys. J Prosthodont. 2004;13:194-9.

20- Taylor R, Maryan C, Verran J. Retention of oral microorganisms on cobalt-chromium alloy and dental acrylic resin with different surface finishes. J Prosthet Dent. 1998;80:592-7.

21- Unlü A, Altay OT, Sahmali S. The role of denture cleansers on the whitening of acrylic resins. Int J Prosthodont. 1996;9:266-70. 22- Webb BC, Thomas CJ, Whittle T. A 2-year study of Candidaassociated denture stomatitis treatment in aged care subjects. Gerodontology. 2005;22:168-76. 